\title{
ハイフィンチューブ碁盤目配列の熱伝達率に対する暫定整理式*
}

\author{
橋詰健 一*1

\section{A Provisional Heat Transfer Correlation for High-finned Tubes in Inline Arrangement}

\author{
Kenichi HASHIZUME*2 \\ ${ }^{* 2}$ Department of Intelligent Machine Engineering, Hiroshima Institute of Technology, \\ 2-1-1 Miyake, Saeki-ku, Hiroshima-shi, Hiroshima, 731-5193 Japan
}

\begin{abstract}
A heat transfer correlation was proposed for inline-arranged high-finned tubes. This correlation was based on the Bell-model, where two stream assumption is used, the primary stream and the bypass stream. In the proposed correlation, the actual heat transfer coefficient between fin and the primary stream was assumed to be predicted by the generally accepted correlation for staggered arrangements, and a correction factor was introduced, which corrects the bypass flow effect. Comparing existing experimental data, the correction factor was determined as a function of the ratio of fin spacing to fin height and of the Reynolds number. The proposed correlation showed good agreements with experimental data of plain and also serrated fins.
\end{abstract}

Key Words : Heat Transfer, Extended Heat Transfer Surface, Forced Convection, Heat Exchanger

\section{1. 緒言}

伝熱管の外面にりほん状の金属片(フィン)を巻き付 けたハイフィンチューブを用いる熱交換器において, 碁盤目配列ははん用の污れ除去装置を使用できること から排熱回収熱交換器などに採用されている(1) が一 般的にはあまり好まれない。その理由の一つには碁盤 目配列の熱伝達率の予測が困難(2) なことがある。千 鳥配列の熱伝達率については設計に広く使用されてい る標準的な整理式が存在する．ところが碁盤目配列の 熱伝達率についてはSchmidt の整理式(3) 以降には, より高精度な整理式の作成は試みられていない.

碁盤目配列に対する熱伝達率整理式の作成を困難に しているのは，この配列に特有のチューブ間を素通り するバイパス流の存在 ${ }^{(4)(5)}$ である. バイパス流はフィ ンと熱交換せずに管群から流出し，熱交換した流体 (主流)と管群の出口で合流する．したがって，管群の 入口出口の流体温度に基づく対数平均温度差によって 評価される熱伝達率は実際の熱伝達率と直ちには結び

\footnotetext{
* 原稿受付 2005 年 3 月 22 日.

*1 正員, 広島工業大学工学部(画 731-5193 広島市佐伯区三宅 2-1-1).

E-mail : hashizme@me.it-hiroshima.ac.jp
}

つかない. Bell ら (4)(5) は碁盤目配列の熱伝達率がフィ ンと主流との間の実際の熱伝達率, 主流とバイパス流 の流量比，および両流の交換量により定まるとしたモ デル (Bell モデル)を提唱したが, 熱伝達率整理式の作 成には至っていない，そこで本報では千鳥配列に対す る熱伝達率に補正項を導入した暫定的な碁盤目配列の 熱伝達率整理式を提案する。図 1 に本報で対象とする ハイフィンチューブの形状を示す.

\section{記 号}

$$
\begin{aligned}
d_{f} & : \text { フィンの外径 } \\
d_{o} & : \text { 素管の外径(フィンの根元直径) } \\
h & : \text { フィン高さ } \\
N & : \text { 流れ方向の管配列段数 }
\end{aligned}
$$

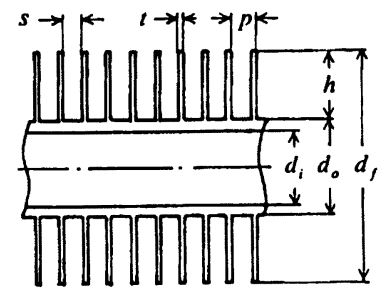

Fig. 1 Configuration of high-finned tube 
$N u$ : ヌッセルト数 $=\alpha_{o} d_{o} / \lambda$

p:フィンピッチ

$P_{l}:$ 流れ方向の管配列ピッチ

$P_{t}:$ 流れ直角方向の管配列ピッチ

$\operatorname{Pr}:$ プラントル数

$R e:$ レイルズ数 $=u_{m} d_{o} / \nu$

$s:$ フンすきま $=p-t$

$t:$ フィン厚さ

$u_{m}:$ 管群内の最小流路断面における流速

$\alpha_{o}$ : フィン側全表面積を基準とした熱伝達率

$\lambda:$ 流体の熱伝導率

$\nu:$ 流体の動粘性係数

$\sigma$ : 面積増倍係数 ＝フィン側全表面積/フィン

巻付け前の素管表面積

\section{2. 暫定整理式作成の背景}

本報で提案する暫定整理式は

$N u_{\text {inline }}=F \cdot N u_{\text {staggerd }}$

の形である.ここで $N u_{\text {inline }}$ は碁盤目配列のヌッセル 卜数, $N u_{\text {staggered }}$ は千鳥配列のヌッセルト数, $F$ は実 験デー夕との比較から定める補正項である。この形の 整理式作成には以下のような背景がある。

（1）碁盤目配列におけるフィン周りの実際の熱伝 達率は千鳥配列の值に近い。

Bell ら (4) (6) は碁盤目配列における実際の熱伝達率 が千鳥配列の值に極めて近いことを見いだした。ま
た, Hashizume ${ }^{(7)}$ の単管加熱の実験でも両者はほぼ

同じ値となった。

（2）碁盤目配列の熱伝達率の千鳥配列に対する低 下の度合いはフィン密度とレイノルズ数に依存する.

Rabas ら (1) は碁盤目配列の熱伝達率に隣接するチ ューブとのフィン間距離に依存しないこと，および, レイノルズ数が大きくなるにつれて碁盤目配列の熱伝 達率が千鳥配列の值に近づいてゆくことを見いだし た。前者からは補正項 $F$ がフィン密度を表す影響因 子の関数となり, 後者からはこれがレイノルズ数の関 数にもなると予測される.

（3）千鳥配列の熱伝達率に対しては標準的な整理 式が存在する.

フィン表面が平たんなプレーンフィンについては次 の Handbook of Heat Exchanger Design の推奨式(8) が広く設計に使用されている。

$$
N u=C\left(\frac{p}{d_{o}}\right)^{0.18}\left(\frac{h}{d_{o}}\right)^{-0.14}\left(\frac{P_{t}}{P_{l}}\right)^{0.2} \operatorname{Re}^{m} \operatorname{Pr}^{n}
$$

$$
\begin{aligned}
C= & 0.19, m=0.65, n=0.33 \\
& : 1 \times 10^{2} \leqq \operatorname{Re} \leqq 2 \times 10^{4} \\
C= & 0.05, m=0.8, n=0.36 \\
: & 2 \times 10^{4} \leqq \operatorname{Re} \leqq 2 \times 10^{5} \\
C= & 0.008, m=0.95, n=0.36 \\
& : 2 \times 10^{5} \leqq \operatorname{Re} \leqq 1 \times 10^{6}
\end{aligned}
$$

\begin{tabular}{|c|c|c|c|c|c|c|c|c|c|c|c|c|c|}
\hline & No. & Author(s) & * & $\begin{array}{r}d_{o} \\
{[\mathrm{~mm}]}\end{array}$ & $\begin{array}{c}d_{f} \\
{[\mathrm{~mm}]}\end{array}$ & $\begin{array}{c}t \\
{[\mathrm{~mm}]}\end{array}$ & $\begin{array}{c}p \\
{[m m]}\end{array}$ & $\begin{array}{c}P_{t} \\
{[m m]}\end{array}$ & $\frac{P_{1}}{P_{l}}$ & $\frac{p}{d_{o}}$ & $\frac{s}{h}$ & $\sigma$ & $N$ \\
\hline \multirow{11}{*}{ 뭉. } & $\begin{array}{l}201 \\
202\end{array}$ & $\begin{array}{c}\text { Huber and } \\
\text { Todaro }\end{array}$ & $\frac{I}{S}$ & 33.40 & 62.36 & 3.378 & 8.458 & 76.20 & 1.00 & 0.253 & 0.351 & 6.25 & 7 \\
\hline & 501 & \multirow{10}{*}{ Carnavos } & \multirow{4}{*}{$I$} & \multirow{4}{*}{9.525} & \multirow{4}{*}{19.05} & \multirow{10}{*}{0.203} & \multirow{6}{*}{0.845} & 30.17 & 1.27 & \multirow{4}{*}{0.0887} & \multirow{4}{*}{0.135} & \multirow{4}{*}{18.1} & \multirow{10}{*}{10} \\
\hline & 502 & & & & & & & 27.00 & 1.13 & & & & \\
\hline & 503 & & & & & & & & 1.00 & & & & \\
\hline & 504 & & & & & & & 23.83 & 1.15 & & & & \\
\hline & 505 & & $I$ & & & & & 13.51 & 1.13 & \multirow{4}{*}{$\frac{0.177}{0.111}$} & \multirow{2}{*}{0.270} & \multirow{2}{*}{9.66} & \\
\hline & 506 & & $S$ & 4.775 & 9.525 & & & 15.09 & 1.47 & & & & \\
\hline & 507 & & $I$ & \multirow{4}{*}{9.525} & \multirow{4}{*}{19.05} & & \multirow{2}{*}{1.059} & 27.00 & 1.13 & & & & \\
\hline & 508 & & $S$ & & & & & 30.16 & 1.46 & & 0.180 & 14.7 & \\
\hline & 509 & & $I$ & & & & & 27.00 & 1.13 & 0148 & & & \\
\hline & 510 & & $S$ & & & & 1.412 & 30.16 & 1.46 & 0.148 & 0.254 & 11.3 & \\
\hline \multirow{9}{*}{ 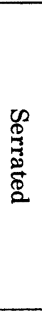 } & 101 & \multirow{3}{*}{$\begin{array}{l}\text { Weierman } \\
\text { et al. }\end{array}$} & & 31.75 & 82.55 & \multirow{3}{*}{1.219} & 4.115 & 93.73 & 1.00 & 0.130 & 0.114 & 19.7 & 5 \\
\hline & 104 & & $I$ & & & & & & 1.00 & & & & 7 \\
\hline & 105 & & $S$ & 50.8 & 102.4 & & 4.274 & 114.3 & 1.15 & 0.0841 & 0.118 & 16.7 & 4 \\
\hline & 301 & Ackerman & $I$ & & & & & & 1.11 & & & & \\
\hline & $\frac{302}{303}$ & and & $S$ & 47.63 & 98.43 & 3.175 & 12.70 & 127.0 & 1.43 & 0.267 & 0.375 & 4.36 & 8 \\
\hline & $\begin{array}{l}303 \\
304\end{array}$ & Brunsvold & $s$ & & & & & & $\begin{array}{l}1.43 \\
1.54 \\
\end{array}$ & & & & \\
\hline & 401 & & $I$ & & & & & 42.27 & 1.21 & & & & 21 \\
\hline & 402 & and & & 12.83 & 25.53 & 0.540 & 2.572 & 36.68 & 1.99 & 0.201 & 0.320 & 7.88 & $?$ \\
\hline & 403 & Jallouk & $S$ & & & & & 27.51 & 1.25 & & & & 14 \\
\hline
\end{tabular}

また,フィンの外周部に切込みを入れたセレーテッ

Table 1 Data sources ${ }^{(1)}$ 
ドフィンに対しては Weiermanの方法(9)(10) がある.

$$
\begin{aligned}
N u= & 0.23\left[0.55+0.45 \exp \left(-0.35 \frac{h}{s}\right)\right]\left(\frac{d_{f}}{d_{o}}\right)^{0.5} \\
\times & {\left[0.7+\left\{0.7-0.8 \exp \left(-0.15 N^{2}\right)\right\}\right] } \\
\times & \exp \left(-\frac{P_{l}}{P_{t}}\right) \operatorname{Re}^{0.65} \operatorname{Pr}^{1 / 3} \\
& : 2 \times 10^{3} \leqq \operatorname{Re} \leqq 5 \times 10^{5} \quad \ldots \ldots \ldots \ldots \cdots \cdots(3)
\end{aligned}
$$

\section{3. 検討対象とする実験データ}

碁盤目配列の熱伝達について検討した Rabas ら ${ }^{(1)}$ が収集したデータのうち熱伝達率が管配列段数 $N$ の 影響を受けない大管群として見なせる $N \geqq 5$ のデータ を表 1 に示す.これらの中には現在入手困難な出典も あるので本報では Rabas らが図示している実験点を 貫く線の值を実験データとする.

碁盤目配列の熱伝達率を式（1）の形で整理するため には同一のチューブを用いた千鳥配列の実験データが 標準的な整理式で精度よく再現できることが条件とな るので，まず最初に千鳥配列のデー夕を検討する．図 2 は熱伝達率を $N u / \mathrm{Pr}^{1 / 3}$ の形で式 ( 2 )または式(3) と比較した結果である. 図 2(a)プレーンフィンにつ いてはNo. 202 の実験データが計算值よりも平均 $32 \%$ も高い值を示している．これはフィン厚さがプレ ーンフィンとして一般的に使用される $0.2 \sim 1.2 \mathrm{~mm}$ に比べてかなり厚いことによると思われるので, 同一 のチューブを使用しているNo. 201 は検討対象から除 外する.図 2(b)セレーテッドフィンについては No. 402 とNo. 403 の実験データがやはり計算值より も平均 $32 \%$ 以上も高い.これは素管の外径がセレー テッドフィンチューブとして一般的に使用される $d_{o}>25 \mathrm{~mm}$ よりもかなり小さいためと思われるので, 同一のチューブを使用しているNo. 401 も検討対象か ら除外する。他の実験デー夕は式（2）または式（３）に よる計算值と $\pm 15 \%$ 以内の精度で一致している.

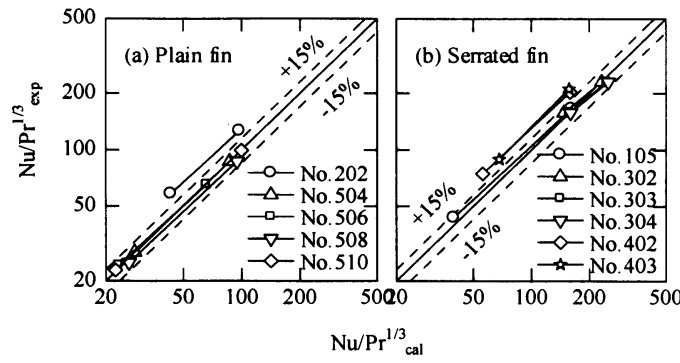

Fig. 2 Comparison of data in staggered arrangements with Eq. ( 2 ) for plain fins and with Eq. (3) for serrated fins

\section{4. 碁盤目配列補正項の導出}

$4 \cdot 1$ プレーンフィン 式(1)の補正項 $F$ を求め るためにNo. 501〜509 について実験デー夕と計算值 との比 $R_{\text {plain }} \quad$ ：碁盤目配列の実験デ一夕/式 (2)に よる計算值］を求めた結果を図 3 に示す. 図 3 より, レイノルズ数が大きくなるにつれて比 $R_{\text {plain }}$ が 1 に近 づいてゆくことがわかる。これは Bell モデルにおい て主流とバイパス流の交換量がレイノルズ数とともに 増加してゆくことを意味している. 図 3 の結果を

$$
R_{\text {plain }}=a R e^{0.275}
$$

としたとき, 係数 $a$ の值は図 4 のようになった．比較 したパラメータ(図 4 の横軸) はいずれもフィン密度を

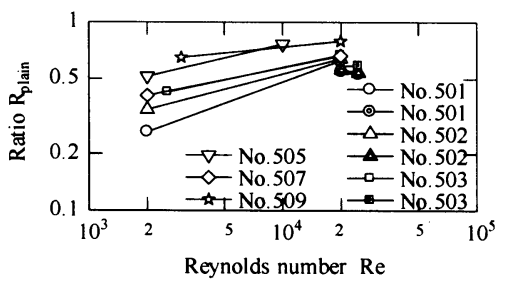

Fig. 3 Ratio of experimented heat transfer coefficients in inline arrangements to calculated values after Eq. (2)

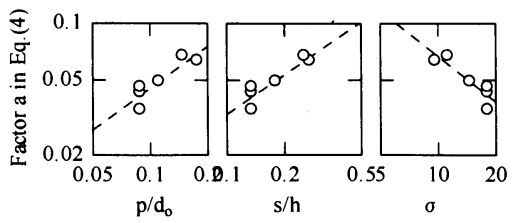

Fig. 4 Factor $a$ in Eq. ( 4 )

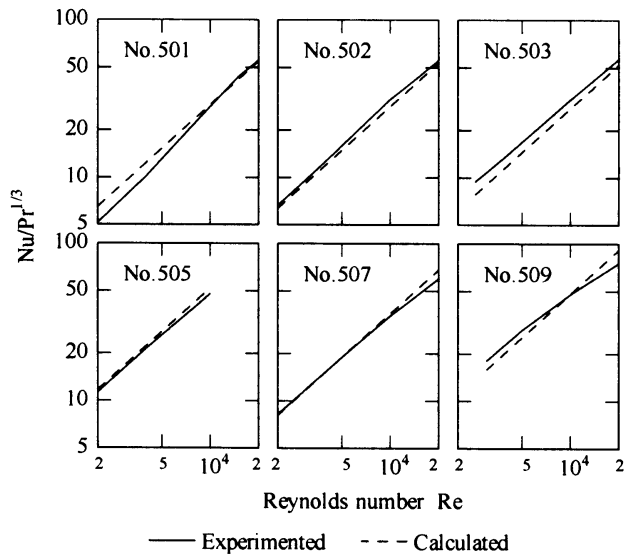

Fig. 5 Comparison of data in inline arrangements with calculated values after Eqns. (1), (2) and (5) 


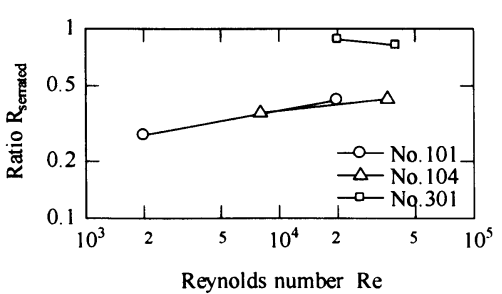

Fig. 6 Ratio of experimented heat transfer coefficients in inline arrangements to calculated values after Eq. ( 3 )

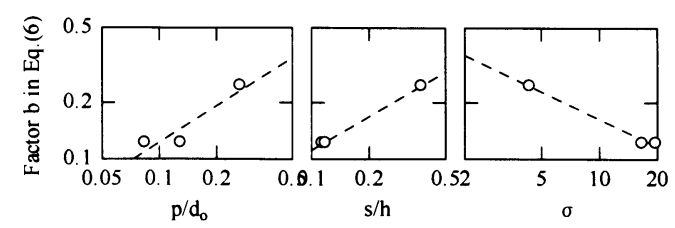

Fig. 7 Factor $b$ in Eq. (6)

表すものであるが相関の度合いに有意差がみられない ので,ここでは代表として $s / h$ をとれば式 ( 1 )におけ る補正項 $F$ は

$$
F_{\text {plain }}=0.165\left(\frac{s}{h}\right)^{0.70} R e^{0.275}
$$

として定まる。この式の意味するところは, フィン密 度が大きくなれば $(s$ が小さくなれば)流体はフィン間 を通りにくくなるのでバイパス流が増加して熱伝達率 が千鳥配列よりも小さくなるということである. 図 5 に実験データと計算値との比較を示す。ここで計算值 は式(1)における $N u_{\text {staggered }}$ に式(2)を用い, $F に$ 式( 5 )を用いて算出したもので, 両者は $\pm 20 \%$ 範囲 内で一致している.

$4 \cdot 2$ セレーテッドフィン セレーテッドフィン について実験デー夕と計算值との比 $R_{\text {serrated }}[=$ 碁盤 目配列の実験デー夕/式 ( 3 )による計算値]を求めた 結果が図 6 である.No. 301 ではレイノルズ数に対す る依存性が逆になっているがこれは比 $R_{\text {serrated }}$ が 1 に近い值であるので無視し

$$
R_{\text {serrated }}=b R e^{0.12}
$$

として係数 $b$ を求めてみると図 7 のようになった. ここでもプレーンフィンの場合と同様にパラメータの 代表として $s / h$ をとれば式 $(1)$ における補正項 $F$ は

$$
F_{\text {serrated }}=0.44\left(\frac{s}{h}\right)^{0.60} R e^{0.12}
$$

として定まる.図 8 に実験データと計算值との比較を 示す.ここで計算值は式（1）におけるN $N u_{\text {staggered }}$ に

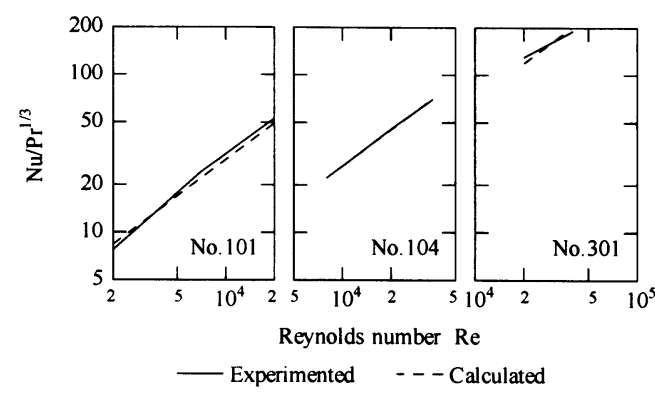

Fig. 8 Comparison of data in inline arrangements with calculated values after Eqns. (1), (3) and ( 7 )

式 (3)を用い, $F$ に式 $(7)$ を用いて算出したもので, 両者は土10\%の範囲内で一致している(No. 104 に いては土1\%以内の一致で, 図 8 では実線と破線が重 なっている).

\section{5. 結言}

碁盤目配列されたハイフィンチューブの熱伝達率に 対する暫定整理式を提案した，適用範囲は流れ方向の 管配列段数が五段以上の大管群で, 同一のチューブを 千鳥配列にした場合に式（2）または式（３）により熱伝 達率を予測できることが条件となる，碁盤目配列の熱 伝達は Bell モデルによって説明できよう。しかしな がらこのモデルによる整理式の作成にはさらに相当の 年月を要すると思われるので，それまでの間はここで 提案した暫定整理式を活用していただきたい。また， 碁盤目配列の熱伝達率に関する実験データは Rabas ら(1)が収集したもの以外には見当たらないので,さら なるデータの蓄積も望まれる。

\section{文献}

(1) Rabas, T. J. and Huber, F. V., Heat Trans. Eng., 10-4 (1989), 19-29.

(2) 橋詰健一, 機械の研究, 56-8 (2004), 885-889.

(3) Schmidt, Th. E., Kältetech., 15-12 (1963), 370-378.

(4) Bell, K. J. and Kegler, W. H., AIChE Symp. Ser., 74174 (1978), 47-52.

(5) Yang, X. and Bell, K. J., AIChE Symp. Ser., 89-295 (1993), 285-292.

(6) Weierman, C., Taborek, J. and Marner, W. J., AIChE Symp. Ser., 74-174 (1978), 39-46.

(7) Hashizume, K., Heat Trans. Eng., 3-2 (1981), 15-20.

(8) Hewitt, G.F., ed., Handbook of Heat Exchanger Design, (1992), Begell House, 2. 5. 3.

(9) Weierman, C., Oil Gas J., 6 (1976), 94-100.

(10) Breber, G., AIChE Symp. Ser., 87-283 (1991), 383-390. 